AperTO - Archivio Istituzionale Open Access dell'Università di Torino

\title{
Hydrogen storage of Mg-Zn mixed metal borohydrides
}

\section{This is the author's manuscript}

Original Citation:

Availability:

This version is available http://hdl.handle.net/2318/151489

since 2016-06-22T17:08:18Z

Published version:

DOI:10.1016/j.jallcom.2013.12.258

Terms of use:

Open Access

Anyone can freely access the full text of works made available as "Open Access". Works made available under a Creative Commons license can be used according to the terms and conditions of said license. Use of all other works requires consent of the right holder (author or publisher) if not exempted from copyright protection by the applicable law. 
This Accepted Author Manuscript (AAM) is copyrighted and published by Elsevier. It is posted here by agreement between Elsevier and the University of Turin. Changes resulting from the publishing process - such as editing, corrections, structural formatting, and other quality control mechanisms - may not be reflected in this version of the text. The definitive version of the text was subsequently published in JOURNAL OF ALLOYS AND COMPOUNDS, 615, 2014, 10.1016/j.jallcom.2013.12.258.

You may download, copy and otherwise use the AAM for non-commercial purposes provided that your license is limited by the following restrictions:

(1) You may use this AAM for non-commercial purposes only under the terms of the CC-BY-NC-ND license.

(2) The integrity of the work and identification of the author, copyright owner, and publisher must be preserved in any copy.

(3) You must attribute this AAM in the following format: Creative Commons BY-NC-ND license (http://creativecommons.org/licenses/by-nc-nd/4.0/deed.en), 10.1016/j.jallcom.2013.12.258

The publisher's version is available at:

http://linkinghub.elsevier.com/retrieve/pii/S092583881400019X

When citing, please refer to the published version.

Link to this full text:

http://hdl.handle.net/2318/151489 


\title{
Hydrogen storage of $\mathrm{Mg}-\mathrm{Zn}$ mixed metal borohydrides
}

\author{
G.N. Kalantzopoulos a, J.G. Vitillo b, E. Albanese b, E. Pinatel b, B. Civalleri b, S. Deledda \\ a, S. Bordiga b, M. Baricco b, B.C. Hauback a
}

a Institute for Energy Technology, Physics Department, P.O. Box 40, NO-2027 Kjeller, Norway

b Dipartimento di Chimica and NIS, Università di Torino, Via P.Giuria 7-9, I-10125 Torino, Italy

\begin{abstract}
On the basis of DFT results on the ideal amount of $Z n$ required to dissolute into the aphase of $\mathrm{Mg}(\mathrm{BH} 4) 2$ (space group P6122) and experimental results recently presented in the literature, mixtures of a- $\mathrm{Mg}(\mathrm{BH} 4) 2$ and $\mathrm{ZnCl} 2$ have been prepared by ball-milling, reactive milling and cryo-milling in Mg:Zn starting ratios of 1:0.33, 1:0.2 and 1:0.1. Samples have been characterized with different experimental techniques (PXD, TGA, TPD with RGA and desorption kinetics in a Sieverts apparatus). All the as-milled samples exhibited a $\mathrm{H} 2$ release beginning approximately at 125 _, indicating a significant decrease in the decomposition temperature compared to pure $\mathrm{Mg}(\mathrm{BH} 4) 2$. With the exception of the $\mathrm{Mg}(\mathrm{BH} 4) 2-0.33 \mathrm{ZnCl} 2$ sample ball-milled under 1 bar $\mathrm{Ar}$ for $3 \mathrm{~h}$ that showed a small B2H6 release around 120_C, all samples are free of B2H6 emissions. Results from desorption kinetics at 195 _C suggest a strong relation between the amount of $\mathrm{ZnCl} 2$ in the starting mixture and the weight loss.
\end{abstract}

\section{Introduction}

$\mathrm{Mg}(\mathrm{BH} 4) 2$ is an interesting candidate material for hydrogen storage applications due to its high gravimetric capacity of 14.9 $\mathrm{H} 2 \mathrm{wt} \%$ [1]. Recently, it was demonstrated that depending on the $\mathrm{Mg}(\mathrm{BH} 4) 2$ polymorph, the total $\mathrm{H} 2$ content can be further increased by adding the amount of $\mathrm{H} 2$ that physisorbs under cryogenic conditions, resulting in a total capacity up to $17.9 \mathrm{wt} \%$ [2]. Despite its high gravimetric capacity, $\mathrm{Mg}(\mathrm{BH} 4) 2$ exhibits slow desorption kinetics and its decomposition temperature is still too high to allow coupling with Proton-Exchange Membrane Fuel Cells (PEM-FC) in hydrogen storage applications. Different methods have been attempted to destabilize pure complex hydrides: anion substitution, cation substitution with mixed metal borohydrides formation, nanoconfinement and formation of reactive hydride composites [3-5]. Very few examples exist in the literature regarding destabilization of $\mathrm{Mg}(\mathrm{BH} 4) 2$ by substitution of either $\mathrm{Mg} 2+$ or $1 / 2 \mathrm{BH} 4$ _. Mixing different ratios of $\mathrm{Mn}(\mathrm{BH} 4) 2$ and a-Mg(BH4)2 $\mathrm{Mn}-$ Mg substitution in a-Mg(BH4)2 up to $10 \mathrm{~mol} \%$ at room temperature was observed [6]. Hino et al. observed halide substitution of $1 / 2 \mathrm{BH} 4$ by $\mathrm{Cl}$ or $\mathrm{Br}$ in the lattice of b-Mg(BH4)2 after annealing a milled mixture of a- $\mathrm{Mg}(\mathrm{BH} 4) 2$ and $\mathrm{MgX} 2(\mathrm{X}=\mathrm{Cl}, \mathrm{Br})$ resulting in a reduction in the temperature of hydrogen desorption [7]. Recently, theoretical calculations combined with experimental work on $\mathrm{Mg}-\mathrm{Zn}$ mixed borohydrides showed that a- $\mathrm{Mg}(\mathrm{BH} 4) 2$ can be efficiently destabilized by adding a suitable amount of $\mathrm{Zn}$ [8]. Selecting $\mathrm{ZnCl} 2$ as $\mathrm{Zn}$ source and ball-milling it with a-Mg(BH4)2 in a Mg:Zn 1:0.7 ratio, we observed the formation of a mixed metal borohydride 
with $\mathrm{Zn} 2+$ substituting $\mathrm{Mg} 2+$ in the a-Mg(BH4)2 lattice and forming a $\mathrm{Mg}\left(1 \_\mathrm{x}\right) \mathrm{Znx}(\mathrm{BH} 4) 2$ solid solution with $\mathrm{x}=0.4$. Theoretical calculations predicted a value of $\mathrm{x}=0.2$ as the optimum ratio for the mixed system, with an estimated enthalpy of decomposition close to 30 kJ mol_1 H2, which could provide hydrogen sorption at room conditions. In this study, the destabilization effect of $\mathrm{ZnCl} 2$ on a$\mathrm{Mg}(\mathrm{BH} 4) 2$ is investigated by ball-milling the starting materials in Mg:Zn ratios of 1:0.10, 1:0.20 and 1:0.33. The as-milled systems are characterized by means of Powder X-ray Diffraction (PXD), Thermo-Gravimetric Analysis (TGA), Thermal Programmed Desorption (TPD) with Residual Gas Analysis (RGA) and the results are discussed and compared with the Mg:Zn 1:0.7 samples reported previously. Finally, the desorption kinetics of the systems at $195 \_$_ is assessed with a Sieverts apparatus.

\section{Experimental methods}

Mixtures of a-Mg(BH4)2 (synthesized at Karlsruhe Institute of Technology, Karlsruhe, Germany) with $\mathrm{ZnCl} 2$ (99\% purity, Sigma Aldrich) were ball-milled either at room temperature or at liquid nitrogen temperature (cryo-milling). Room-temperature ball milling was carried out in a Fritsch Pulverisette 6 Monomill at 400 rpm either under inert ( 1 bar Ar for 3 h) or reactive (50 bar H2 in an Evico Magnetics high-pressure vial for $12 \mathrm{~h}$ ) atmosphere using stainless steel balls and vials (ball-to-powder ratio 100:1). Cryo-milling in Ar at liquid N2 temperature was performed in a SPEX 6770 Freezer/Mill using a specially designed stainless steel vial, in order to minimize oxygen and nitrogen contaminations. The mass ratio between the stainless steel cylindrical impactor and the powder mixture was 15:1 and the impact frequency during milling was set at $30 \mathrm{~Hz}$. All sample handling andpreparation were carried out under inert Ar atmosphere in an MBraun Unilab glove box fitted with a recirculation system and gas/humidity sensors. Oxygen and water levels were kept below 1 ppm at all times.

Powder X-ray Diffraction (PXD) measurements were performed in a DebyeScherrer geometry using a Panalytical X'Pert Pro Multipurpose Diffractometer, equipped with Ni filtered $\mathrm{Cu}$ source. Powder samples were sealed into boron silica glass capillaries of internal diameter $0.8 \mathrm{~mm}$ in nitrogen atmosphere, which give a broad peak in the pattern centered around $2 \mathrm{~h}=22$. Patterns were taken by spinning capillaries in a $2 \mathrm{~h}$ range $2 \_-100 \_$at a scanning step of 0.016 and with a scan speed of 0.010_s. Rietveld refinement of PXD patterns has been carried out with MAUD software [9].

Thermo Gravimetric Analysis (TGA) experiments were performed with a Netzsch STA 449 F3 Jupiter instrument. Samples were measured in Al crucibles with pierced lids of the same material. The samples were heated between $30 \_\mathrm{C}$ and $600 \_$, with a heating rate of 2 _C min_1 under argon gas $(50 \mathrm{ml} / \mathrm{min})$. The measurements were baseline corrected by the Proteus software package. Temperature-Programmed Desorption (TPD) with Residual Gas Analysis (RGA) spectra were measured in an in-house developed setup under vacuum (10_5 mbar) and between RT and 600 _C with a constant heating rate of 2 _C min_1. Simultaneous RGA was measured with a MULTIVISON IP mass spectrometer detector system coupled to a PROCESS Eye analysis package from MKS Instruments. Dehydrogenation and hydrogenation kinetic measurements were carried out in a calibrated in-house built volumetric apparatus. Approximately $200 \mathrm{mg}$ of sample 
was inserted in a sample holder and placed under static vacuum. The sample holder is coupled with a pneumatic valve that keeps the sample in Ar during its transport from the glove box to the Sieverts apparatus. During dehydrogenation, each sample was heated from room temperature up to 195 _C at 20 _C min_1 and then remained under isothermal conditions for $24 \mathrm{~h}$. Hydrogenation took place after the end of dehydrogenation without evacuating the sample-holder and under the same isothermal conditions. For each hydrogenation experiment the $\mathrm{H} 2$ pressure was 95 bar. Ultra-pure 6.0 grade $\mathrm{H} 2$ was used.

\section{Results and discussion}

On the basis of calculations recently presented in the literature [8], mixtures of a-Mg(BH4)2 and $\mathrm{ZnCl} 2$ have been ball-milled in different ratios. Pure compounds with a $\mathrm{Mg}: \mathrm{Zn}$ ratio 1:0.33 have been ball-milled at room temperature under 1 bar Ar for $3 \mathrm{~h}(\mathrm{~S} 1)$ and under 50 bar $\mathrm{H} 2$ for $12 \mathrm{~h}$ (S2). Mixtures with $\mathrm{Mg}: \mathrm{Zn}$ ratios of 1:0.2 (S3) and 1:0.1 (S4) were cryo-milled for $1 \mathrm{~h}$.

Fig. 1 reports the PXD patterns for samples S1, S3 and S4. The patterns of pure a-Mg(BH4)2 and $\mathrm{ZnCl} 2$ are also provided for reference. Prolonged milling ( $3 \mathrm{~h}$ in $\mathrm{Ar}-\mathrm{S} 1$ or $12 \mathrm{~h}$ in $\mathrm{H} 2-\mathrm{S} 2$ ) results in the conversion of the starting materials to $\mathrm{Zn}$ and $\mathrm{MgCl}$. This is clearly seen in the PXD pattern of $S 1$ in Fig. 1. A small fraction of unreacted a- $\mathrm{Mg}(\mathrm{BH} 4) 2$ is also observed. The PXD pattern of S2 (not shown) displays similar features. The same behavior was reported for the a-Mg(BH4)2 + $\mathrm{ZnCl} 2$ mixture with a 1:0.7 $\mathrm{Mg}: \mathrm{Zn}$ ratio and ball milled in Ar for $12 \mathrm{~h}$ [5]. The PXD patterns of S3 and S4 (Fig. 1) are dominated by the starting materials. In those samples, a partial amount of a- $\mathrm{Mg}(\mathrm{BH} 4) 2$ and $\mathrm{ZnCl} 2$ has reacted towards formation of $\mathrm{Zn}$ and $\mathrm{MgCl}$, similar to $\mathrm{S} 1$. The Rietveld refinement of PXD patterns of S3 and S4 samples provided accurate values of lattice parameters for a-Mg(BH4)2 phase, as reported in Table 1. Results indicate a reduction of unit cell parameters with respect to pure a-Mg(BH4)2, suggesting a small substitution of $\mathrm{Mg} 2+$ by $\mathrm{Zn2}+$ in the borohydride lattice with formation of a $\mathrm{Mg}\left(1 \_\mathrm{x}\right) \mathrm{Znx}(\mathrm{BH} 4) 2$ solid solution. From the observed volume contractions (see Table 1) compared to those calculated for solid solutions as a function of composition [5], a value of $x$ around 0.10 and 0.06 is estimated for samples S3 and S4, respectively. These values are much smaller than those observed for different $\mathrm{Mg}: \mathrm{Zn}$ ratios, as reported in Ref. [5]. Finally, it should be noted that anion substitution, that is Cl_replacing $1 / 2 \mathrm{BH} 4$ _ anions, cannot be ruled out. However, considering the ratio between anionic radii of $1 / 2 \mathrm{BH} 4 \ldots(0.203 \mathrm{~nm})$ and $\mathrm{Cl} \_(0.171 \mathrm{~nm})$, a stronger reduction of the cell volume would be expected. The contraction of the unit cell observed experimentally is therefore more likely related to a cation rather than an anion substitution and the formation of a $\mathrm{Mg}\left(1 \_\mathrm{x}\right) \mathrm{Znx}(\mathrm{BH} 4) 2$ solid solution. The results of TGA measurements on as-milled samples are illustrated in Fig. 2, where the mass loss profile obtained for pure a-Mg(BH4)2 is also reported for reference. All the as-milled samples show mass-loss events which begin at approximately 125 _C and continue up to the end of the temperature scale at 600 _C. Samples S1 and S2 show a similar mass-loss profile, suggesting a 
2-step decomposition mechanism with individual steps occurring in the temperature ranges of 150-180_C and 230-320_C. S1 and

S2 have a maximum mass-loss of 7 and $6 \mathrm{wt} \%$, respectively. This result suggests that $\mathrm{H} 2$ and/or $\mathrm{B} 2 \mathrm{H} 6$ were released during the prolonged milling, similarly to the sample with $\mathrm{Mg}: \mathrm{Zn} \mathrm{1:0.7} \mathrm{ballmilled}$ under the same experimental conditions used for S2 [8]. Sample S3 shows a 1-step mass-loss mechanism that yields $3 \mathrm{wt} \%$ at $250 \_\mathrm{C}$ and $11 \mathrm{wt} \%$ at 450 _. A similar behavior is observed for S4, exhibiting 4 and 14.5 wt\% at 250 _C and $450 \_$C, respectively. The mass loss profile is similar to that of the pureborohydride with a clear shift towards lower temperatures. These results suggest that small amount of $\mathrm{ZnCl} 2$ in the initial mixture is enough to initiate the gas release at 125 _ $\mathrm{C}$ without compromising significantly the total $\mathrm{H} 2$ capacity of the borohydride.

In order to identify the nature of the gas released by the samples during heating and to make sure that the mass-loss observed can be indeed ascribed to $\mathrm{H} 2$ desorption, TPD-RGA measurements were conducted and the results are reported at Fig. 3. Only data for mass $2(\mathrm{H} 2)$ and mass $26(\mathrm{~B} 2 \mathrm{H} 6)$ are illustrated due to the negligible intensity observed for other masses. Fig. 3a shows the results obtained for pure a-Mg(BH4)2 confirming the stepwise desorption observed in the TGA profile (Fig. 2). The delivery of $\mathrm{H} 2$ begins at $190 \_$C, becomes more significant at $250 \_C$ and eventually the main desorption peak is observed at 300 C. At the same time, no $\mathrm{B} 2 \mathrm{H} 6$ is detected in the released gas. On the other hand, the ball-milled mixed samples show a hydrogen release that begins at much lower temperatures than for pure a-Mg(BH4)2 and depends on the amount of $\mathrm{ZnCl} 2$ contained in the starting mixture. Sample S1 (Fig. 3b) exhibits a wide $\mathrm{H} 2$ release distributed from 100 up to $400 \_$, that is the widest temperature range of $\mathrm{H} 2$ release among the examined samples. At 100 _ a bump is observed for both mass 2 and mass 26 suggesting a limited $\mathrm{B} 2 \mathrm{H} 6$ release. This is the only instance among the samples investigated in this work where $\mathrm{B} 2 \mathrm{H} 6$ release is detected. Two main desorption peaks are seen at $180 \_$C and $280 \_C$, in very good agreement with the TGA results. $\mathrm{H} 2$ desorption peaks occurring at the same temperature range as at $\mathrm{S} 1$ are observed for $\mathrm{S} 2$ (Fig. $3 \mathrm{c}$ ). $\mathrm{H} 2$ release begins at 100 C, however it is more intense between 150 and 200 C. No $\mathrm{B} 2 \mathrm{H} \overline{6}$ release was detected throughout the heating treatment. Finally, samples S3 and S4 clearly show one main desorption event at 283 and 288 _ C, respectively (Fig. $3 d$ and e, respectively). The minor desorption peaks observed for pure a-Mg(BH4)2 are missing, suggesting an alteration in the decomposition path of the borohydride. For both samples, the intensity of signal for mass 26 was negligible in all the temperature range.

Finally, in order to quantify the effect of the different amounts of $\mathrm{ZnCl} 2$ in the parent mixture on the desorption kinetics of a$\mathrm{Mg}(\mathrm{BH} 4) 2$, desorption measurements were carried out in a Sieverts apparatus. Fig. 4 shows the desorption profile for the pure a$\mathrm{Mg}(\mathrm{BH} 4) 2$ and the as-milled samples, acquired at 195 C. At this temperature, pure a- $\mathrm{Mg}(\mathrm{BH} 4) 2$ releases $0.5 \mathrm{wt} \%$ after $24 \mathrm{~h}$ 
(Fig. 4a). Sample S4 releases $1 \mathrm{wt} \%$, that is double the amount released by the pure material (Fig. 4b). Under the same conditions, sample S3 releases $1.4 \mathrm{wt} \%$, that is almost three times higher compared to the pure borohydride (Fig. 4c). Practically no difference is observed in the desorption kinetics of S1 and S2, with both samples delivering $2.8 \mathrm{wt} \%$ after $24 \mathrm{~h}$ at 195 _C (Fig. $4 \mathrm{~d}$ and e, respectively). Following the dehydrogenation, each sample was hydrogenated at the same temperature ( $195 \_$C) under 95 bar H2 for $48 \mathrm{~h}$ without any evident absorption taking place.

The results above show that a careful selection of milling conditions and milling time is crucial for producing $\mathrm{Mg}\left(1 \_\mathrm{x}\right) \mathrm{Znx}(\mathrm{BH} 4) 2$ solid solutions from $\mathrm{Mg}(\mathrm{BH} 4) 2$ and $\mathrm{ZnCl} 2$. If the milling is performed at room temperature and for an extended time (over $3 \mathrm{~h}$ ), the starting materials react to form $\mathrm{MgCl} 2$ and $\mathrm{Zn}$ with $\mathrm{H} 2$ and $\mathrm{B} 2 \mathrm{H} 6$ likely being released during milling. The resulting composites ( $\mathrm{S} 1$ and $\mathrm{S} 2$ in this work) contain residual $\mathrm{Mg}(\mathrm{BH} 4) 2$ which desorb $\mathrm{H} 2$ and in some cases $\mathrm{B} 2 \mathrm{H} 6$. The desorption temperature is much lower than that for pure $\mathrm{Mg}(\mathrm{BH} 4) 2$ and the desorption kinetics is faster. However, the amount of hydrogen released during desorption is significantly less than the theoretical capacity of the startingmixtures. A reduced $\mathrm{H} 2$ capacity and the $\mathrm{B} 2 \mathrm{H} 6$ release are major setbacks for practical hydrogen storage applications.

Reducing the milling time down to $1 \mathrm{~h}$ and performing milling at liquid nitrogen temperature limits the extent of the reaction between the starting $\mathrm{Mg}(\mathrm{BH} 4) 2$ and $\mathrm{ZnCl} 2$. Although limited in time, milling still promotes an intimate mixing of the starting materials which results in the formation of $\mathrm{Mg}\left(1 \_\mathrm{x}\right) \mathrm{Znx}(\mathrm{BH} 4) 2$ solid solutions $(x=0.10$ and $x=0.06$ for S3 and S4, respectively). At the same time, in analogy with the synthesis by ball milling of other hydrides [10], the low temperature maintained during milling likely prevents the decomposition of the newly formed solid solutions. The composites containing $\mathrm{Mg}\left(1 \_\mathrm{x}\right) \mathrm{Znx}(\mathrm{BH} 4) 2$ solid solutions show the best hydrogen desorption performances among the samples investigated in this work. A relative fast desorption kinetics is coupled with desorption temperatures which are significantly reduced when compared to pure $\mathrm{Mg}(\mathrm{BH} 4) 2$, without compromising the weight capacity. In addition, no B2H6 is detected in the released gas. This work confirms the destabilization effect reported previously for cryo-milled $\mathrm{Mg}\left(1 \_\mathrm{x}\right) \mathrm{Znx}(\mathrm{BH} 4) 2$ with $\mathrm{x}=0.4$ and predicted by the theoretical calculations on the dissolution of $\mathrm{Zn}$ in $\mathrm{Mg}(\mathrm{BH} 4) 2$. It is worth noting that the optimal destabilization, with an estimated enthalpy of decomposition close to $30 \mathrm{~kJ}$ mol_ $1 \mathrm{H} 2$, is predicted for $x=0.2$, whereas experimental results are only shown for $\mathrm{x}=0.06$ and 0.10 (this work) and $\mathrm{x}=0.40$ [8]. This discrepancy is due to the difficulty of accurately tune the degree of $\mathrm{Zn}$ substitution in the final solid solution, since a fraction of the starting $\mathrm{ZnCl} 2$ is either left unreacted or transformed to metallic $\mathrm{Zn}$. Therefore, the relative content of $\mathrm{Zn}$ in the starting mixture does not correspond to the actual content of $\mathrm{Zn}$ found in the $\mathrm{Mg}\left(1 \_\mathrm{x}\right) \mathrm{Znx}(\mathrm{BH} 4) 2$ solid solution after cryo-milling, as shown in Fig. 5 where the amount of $\mathrm{Zn}$ in the solid solution is plotted against the $\mathrm{Mg}: \mathrm{Zn}$ molar ratio 
in the starting materials for the cryo-milled samples. The data for $\mathrm{Mg}: \mathrm{Zn}$ ratio 0.7 come from Ref. [8]. An almost linear relation between the starting $\mathrm{Zn}$ content and the $\mathrm{Zn}$ substituted in $\mathrm{Mg}(\mathrm{BH} 4) 2$ can be noticed in Fig. 5. From such a linear relation, we should expect the formation of a $\mathrm{Mg}\left(1 \_\mathrm{x}\right) \mathrm{Znx}(\mathrm{BH} 4) 2$ solid solution with $\mathrm{x}=0.2$ for a Mg:Zn starting ratio of about 1:0.35.

In spite of the beneficial effect that the dissolution of $\mathrm{Zn}$ has on the hydrogen desorption in $\mathrm{Mg}(\mathrm{BH} 4) 2$, the reversibility of hydrogen sorption in the $\mathrm{Mg}\left(1_{-} \mathrm{x}\right) \mathrm{Znx}(\mathrm{BH} 4) 2$ solid solution still remains unfulfilled. Since no $\mathrm{B} 2 \mathrm{H} 6$ was detected in the released gas, we can ascribe the irreversibility to the formation of stable B-containing phases.

4. Conclusions

On the basis of DFT results on the ideal amount of $\mathrm{Zn}$ required to dissolute into the a-phase of $\mathrm{Mg}(\mathrm{BH} 4) 2$ and experimental results that we recently presented in the literature, mixtures of a$\mathrm{Mg}(\mathrm{BH} 4) 2$ and $\mathrm{ZnCl} 2$ have been processed by ball-milling, reactive milling and cryo-milling in Mg:Zn ratios of 1:0.33, 1:0.2 and $1: 0.1$, respectively. All the as-milled sampled exhibited mass loss beginning at 125 C. Rietveld refinement showed the formation of $\mathrm{Mg}-\mathrm{Zn}$ mixed metal borohydride. With the exception of the $\mathrm{Mg}(\mathrm{BH} 4) 2-0.33 \mathrm{ZnCl} 2$ sample ball-milled under 1 bar Ar for $3 \mathrm{~h}$ that showed a small $\mathrm{B} 2 \mathrm{H} 6$ release around 120 _C, all the samples were found free of $\mathrm{B} 2 \mathrm{H} 6$ emissions. Desorption kinetics obtained at 195 _C suggest a strong relation between the amount of $\mathrm{ZnCl} 2$ in the starting mixture and the weight loss at this temperature. It was found that $\mathrm{ZnCl} 2$ can significantly destabilize the a-Mg(BH4)2 and create systems that in most cases are free of $\mathrm{B} 2 \mathrm{H} 6$ emissions during the thermal decomposition.

Acknowledgements

M. Fitchtner from KIT, Germany is kindly acknowledged for providing $\mathrm{Mg}(\mathrm{BH} 4) 2$ samples. The research leading to these results has received funding from the European Union's Seventh Framework Programme (FP7/2007-2013) for the Fuel Cells and Hydrogen Joint Technology Initiative under the E.U. project SSH2S (Grant agreement No. 25665).

\section{References}

[1] H.W. Li, Y.G. Yan, S. Orimo, A. Zuttel, C.M. Jensen, Energies 4 (2011) 185-214.

[2] Y. Filinchuk, B. Richter, T.R. Jensen, V. Dmitriev, D. Chernyshov, H. Hagemann, Angew. Chem. Int. Ed. 50 (2011) 11162-11166.

[3] L.H. Rude, T.K. Nielsen, D.B. Ravnsbaek, U. Bosenberg, M.B. Ley, B. Richter, L.M. Arnbjerg, M. Dornheim, Y. Filinchuk, F. Besenbacher, T.R. Jensen, Phys. Status Solidi A - Appl. Mater. Sci. 208 (2011) 1754-1773.

[4] H.W. Li, S. Orimo, Y. Nakamori, K. Miwa, N. Ohba, S. Towata, A. Zuttel, J. Alloys Comp. 446 (2007) 315-318.

[5] S.I. Orimo, Y. Nakamori, J.R. Eliseo, A. Zuttel, C.M. Jensen, Chem. Rev. 107 (2007) 4111-4132.

[6] R. Cerny, N. Penin, V. D’Anna, H. Hagemann, E. Durand, J. Ruzicka, Acta Mater. 59 (2011) 5171-5180. 
[7] S. Hino, J.E. Fonnelop, M. Corno, O. Zavorotynska, A. Damin, B. Richter, M. Baricco, T.R. Jensen, M.H. Sorby, B.C. Hauback, J. Phys. Chem. C 116 (2012) 12482-12488.

[8] E. Albanese, G.N. Kalantzopoulos, J.G. Vitillo, E. Pinatel, B. Civalleri, S. Deledda, S. Bordiga, B.C. Hauback, M. Baricco, J. Alloys Comp. 580 (2013) S282-S286.

[9] S.M.A.H.-R.W. L. Lutterotti, "MAUD (material analysis using diffraction): a user friendly java program for Rietveld texture analysis and more", in: Twelfth International Conference on Textures of Materials (ICOTOM-12), 1999. [10] H.W. Brinks, A. Fossdal, B.C. Hauback, J. Phys. Chem. C 112 (2008) 5658-5661.

Table 1

Lattice constants and unit cell volumes obtained from Rietveld refinement of PXD patterns.

\begin{tabular}{llllll}
\hline Sample & $\mathrm{Mg}: \mathrm{Zn}$ & $a=b(\AA)$ & $c(\AA)$ & $\mathrm{Vol}\left(\AA^{3}\right)$ & $-\Delta \mathrm{V}(\%)$ \\
\hline$\alpha-\mathrm{Mg}\left(\mathrm{BH}_{4}\right)_{2}$ & 0 & 10.336 & 37.089 & 3962 & 0 \\
$\mathrm{~S} 3$ & 0.2 & 10.299 & 36.997 & 3924 & 0.96 \\
S4 & 0.1 & 10.306 & 37.086 & 3938 & 0.60 \\
S3 from Ref. [8] & 0.7 & 10.216 & 36.673 & 3827 & 3.41 \\
\hline
\end{tabular}
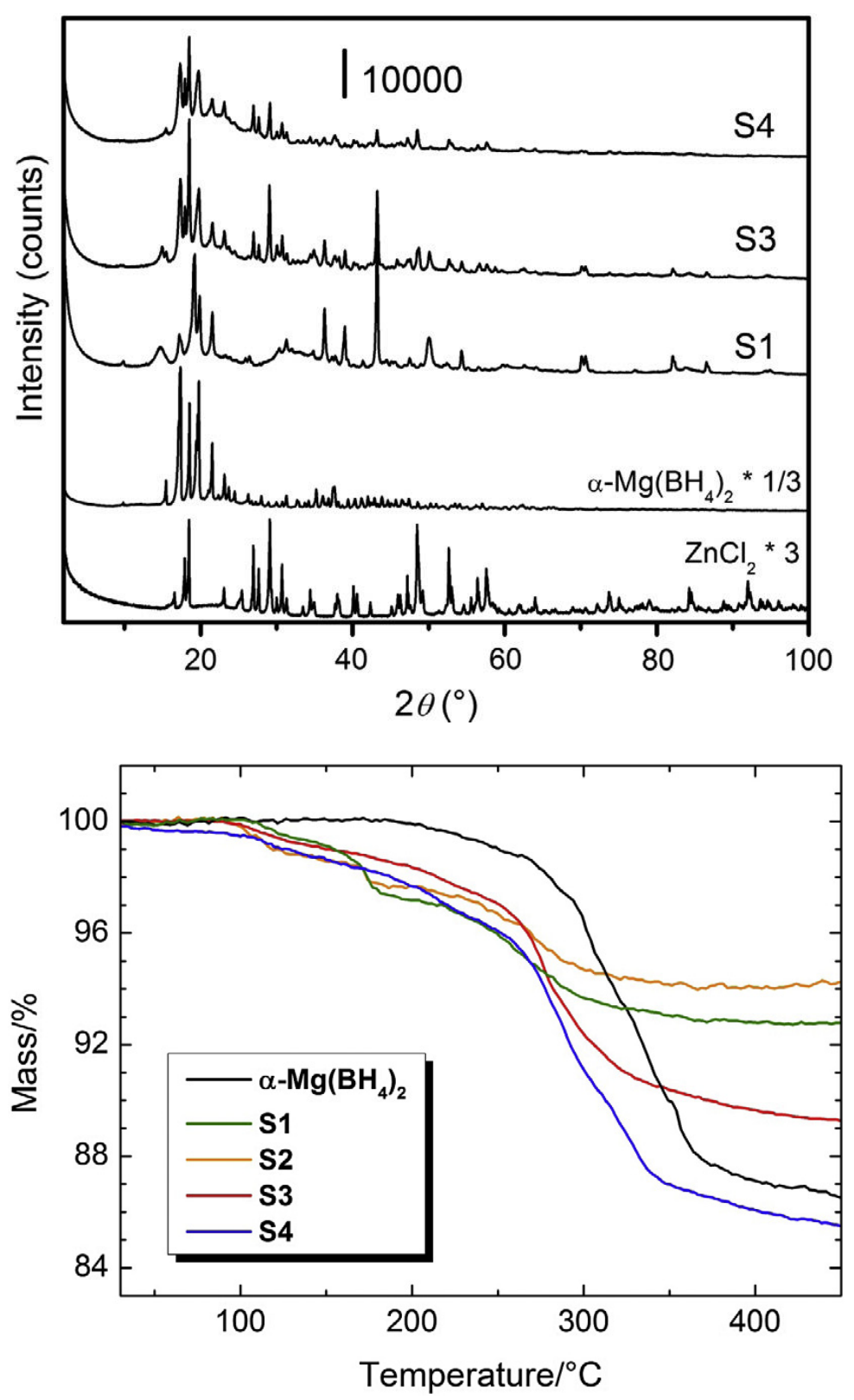


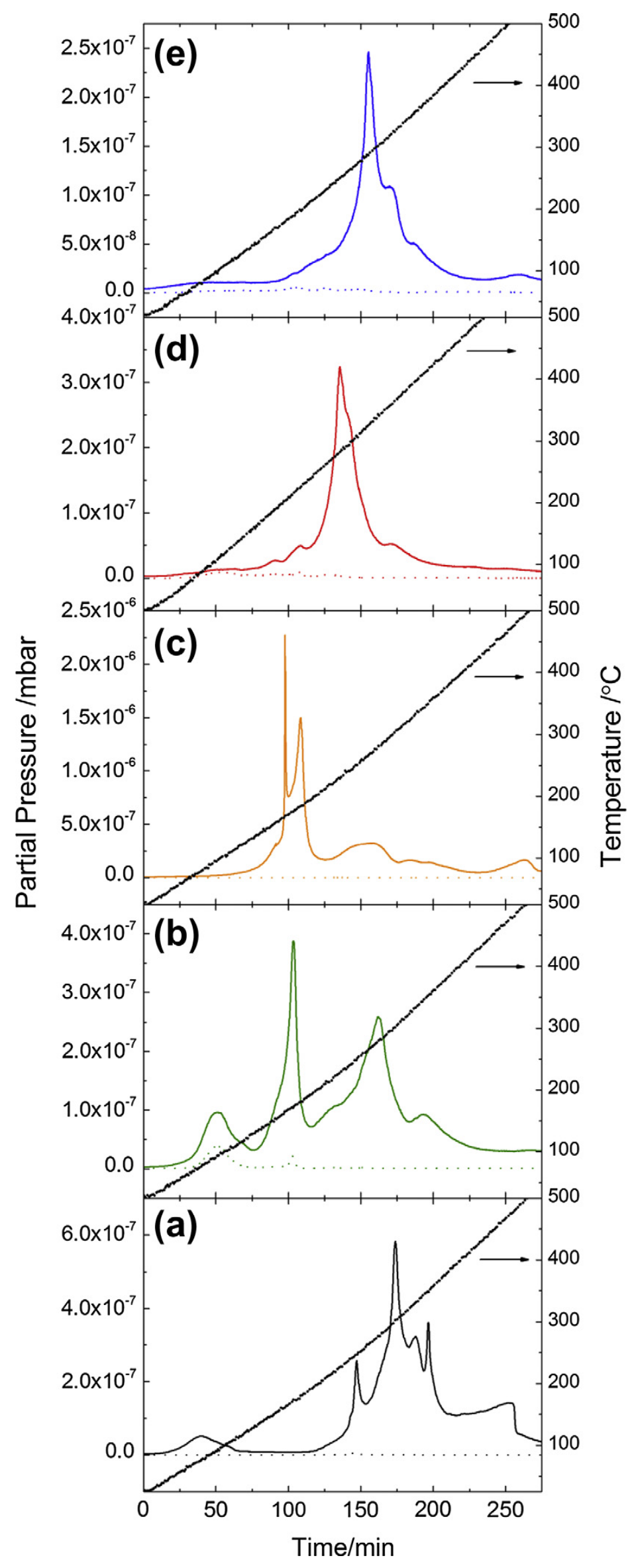



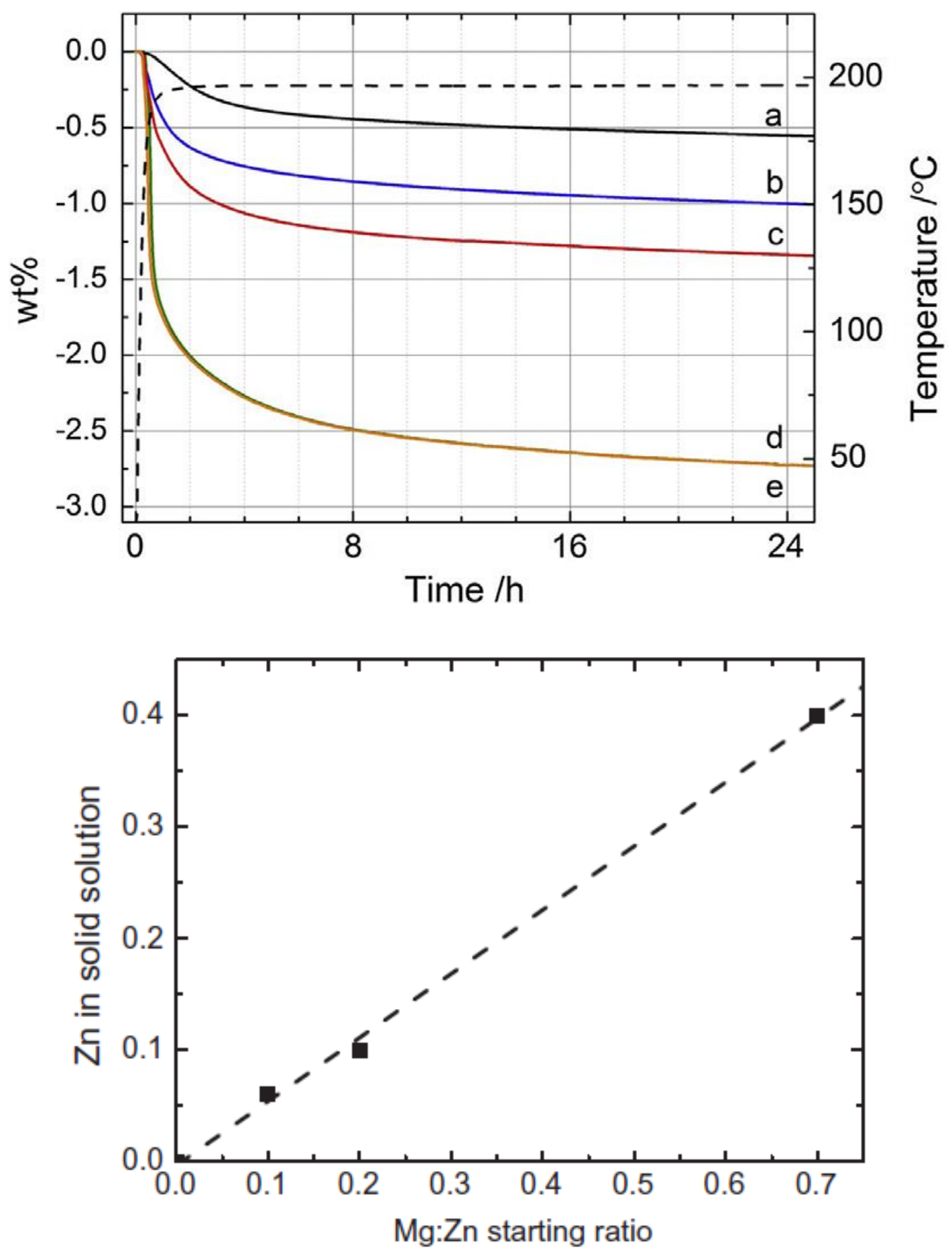

Figure captions

Fig. 1. X-ray diffraction patterns (Cu Ka $1.540598 \AA$ ) of pure a-Mg(BH4)2, pure $\mathrm{ZnCl} 2$ and of samples S1, S3 and S4.

Fig. 2. TGA profiles of pure a-Mg(BH4)2 (black) and of samples $\mathrm{S} 1$ (green), S2 (orange), S3 (red) and S4 (blue). (For interpretation of the references to color in this figure legend, the reader is referred to the web version of this article.)

Fig. 3. TPD-RGA spectra of pure a-Mg(BH4)2 (a), S1 (b), S2 (c), S3 (d) and S4 (e). Continuous line is used for mass $2(\mathrm{H} 2)$ and dotted line for mass $26(\mathrm{~B} 2 \mathrm{H} 6)$. The 
temperature ramps used for the desorption are indicated by continuous black lines.

Fig. 4. Desorption kinetics during the first $25 \mathrm{~h}$ at $195 \mathrm{C}$ for pure a-Mg(BH4)2 (a), S1 (b), S2 (c), S3 (d) and S4 (e). The dashed line indicates the temperature ramp.

Fig. 5. Amount of $\mathrm{Zn}$ in the solid solution vs $\mathrm{Mg}: \mathrm{Zn}$ molar ratio in the starting materials for the cryo-milled samples. The data for Mg: $\mathrm{Zn}$ ratio 0.7 are from Ref. [8]. 